BMJ Open Sport \& Exercise Medicine

\title{
Is the call to reduce heading exposure in professional football to prevent dementia evidence-based?
}

\author{
Vincent Gouttebarge (1D) 1,2,3
}

\begin{abstract}
To cite: Gouttebarge V. Is the call to reduce heading exposure in professional football to prevent dementia evidence-based? BMJ Open Sport \& Exercise Medicine 2021;7:e001076. doi:10.1136/ bmjsem-2021-001076
\end{abstract}

Accepted 16 April 2021

\section{Check for updates}

(c) Author(s) (or their employer(s)) 2021. Re-use permitted under CC BY-NC. No commercial re-use. See rights and permissions. Published by BMJ.

${ }^{1}$ Amsterdam UMC, University of Amsterdam, Department of Orthopaedic Surgery, Amsterdam Movement Sciences, Amsterdam, Netherlands ${ }^{2}$ Amsterdam Collaboration on Health \& Safety in Sports (ACHSS), Amsterdam UMC IOC Research Center of Excellence, Amsterdam, Netherlands ${ }^{3}$ Section Sports Medicine, University of Pretoria, Pretoria, South Africa

Correspondence to Dr Vincent Gouttebarge; v.gouttebarge@amsterdamumc. $\mathrm{nl}$
A Scottish study found in 2019 that the mortality from neurodegenerative diseases, particularly dementia, was higher in former professional footballers than in the general population. ${ }^{1}$ Dementia is a syndrome of progressive deterioration in various brain functions (eg, memory, thinking, ability to perform activities) beyond what might be expected within normal ageing. ${ }^{2}$ Several risk factors for dementia have been established, including ageing, low education, low mental activity, obesity, physical inactivity, depression and traumatic brain injury. ${ }^{2}$ Principally in the wake of the aforementioned Scottish study, professional football stakeholders, former players, charities and media have repeatedly been calling to reduce heading in professional football in order to prevent dementia. However, Is this call currently backed with sufficient and robust epidemiological evidence? This editorial reflects on several key questions that must be answered before we can provide decision-makers with concrete and safe evidence-based guidelines for professional football.

\section{DO WE HAVE SCIENTIFIC EVIDENCE ABOUT THE EXPOSURE TO HEADING IN PROFESSIONAL FOOTBALL?}

Not completely, although some evidence about heading exposure in professional football are available. Analysis of 7147 matches in the 'Big 5' professional European football leagues (Bundesliga, Ligue 1, Premier League, La Liga and Serie A) and one lower tier professional league (English Championship) showed that the number of headers per player ranged from 3.60 (midfielders in Ligue 1) to 9.24 (defenders in English Championship) per match. ${ }^{3}$ Exposure to heading during training across leagues and exposure among female professional footballers remain unknown and should be assessed. Such an exercise should be based on observation as self-reported data cannot be used to quantify individual heading exposure. ${ }^{4}$
Does the scientific evidence show that former players have a higher risk of dementia than the general population?

The retrospective study mentioned showed that the mortality from neurodegenerative diseases, particularly dementia, was higher in Scottish male former professional footballers born between 1900 and 1977 than in the general population. ${ }^{1}$ At the present time, a comparable study in professional football has not been replicated in other continents and countries yet, nor among younger generations or female former footballers. As such, it would not be evidence-based at present time to state that the issue raised in the named study is reflective of an issue in professional football in general. It worth mentioning that evidence is available in other sports such as American Football. ${ }^{5}$

Does the scientific evidence show that heading in professional football causes a higher risk of dementia among former players?

In epidemiology, identifying an association between a determinant (eg, presumed cause) and the outcome under consideration is not enough to prove causality, ${ }^{6}$ That the sun rises every time the cock crows does not imply causality, as the sun would still have risen if the cock had not crowed. In the case of smoking and lung cancer, one can speak of causality: many patients with lung cancer would not have developed lung cancer if they had not smoked. ${ }^{6}$ Concerning heading and dementia in professional football, the Scottish study mentioned previously showed that the mortality from neurodegenerative diseases (especially dementia) among Scottish male former professional footballers was higher than among the general population. ${ }^{1}$ This study was purely nonanalytical observational and did not establish any relationship (causal or not) between sport-related risk factors (eg, heading, head injury) and postfootball dementia. ${ }^{1}$ Therefore, we do not know whether heading in professional 
football causes a higher risk of dementia among former male players in Scotland, nor among former players in other countries.

Do we have scientific evidence about the dose-response relationship between heading in professional football (training and competition) and dementia among professional footballers?

In epidemiology, researchers often explore whether a higher or more prolonged exposure to a determinant (eg, presumed cause) coincides with a higher frequency of the outcome under consideration. For instance, a doseresponse relationship (nonlinear) was found between sedentary time and mortality, with 10 and 12 hours each day spent sedentary being associated with 1.48 and 2.92 times higher risks of death, respectively. ${ }^{7}$ This information is essential to formulate concrete advice, including thresholds for sedentary time and related physical activity. Concerning heading and dementia in professional football, information about exposure is minimal (absent for training), while evidence of any relationship between heading and postfootball dementia is lacking. Therefore, we do not know the dose-response relationship between heading and dementia among professional footballers, and this should be a focus of future research.

Do we have scientific evidence about the exposure to heading in professional football (training and competition) that remains safe or acceptable for players to prevent dementia?

Insight into the dose-response relationship between a determinant (eg, presumed cause) and the health outcome under consideration provides decision-makers with the possibility to define the exposure level beyond which the health risk is acceptable or not. For their recent guidelines on physical activity and sedentary behaviour, the WHO relied on reviews that examined an association (based on levels above or below a threshold of physical activity or sedentary behaviour) and explored the doseresponse relationship between these behaviours and health-related outcomes. ${ }^{8}$ As illustrated in figure 1, for

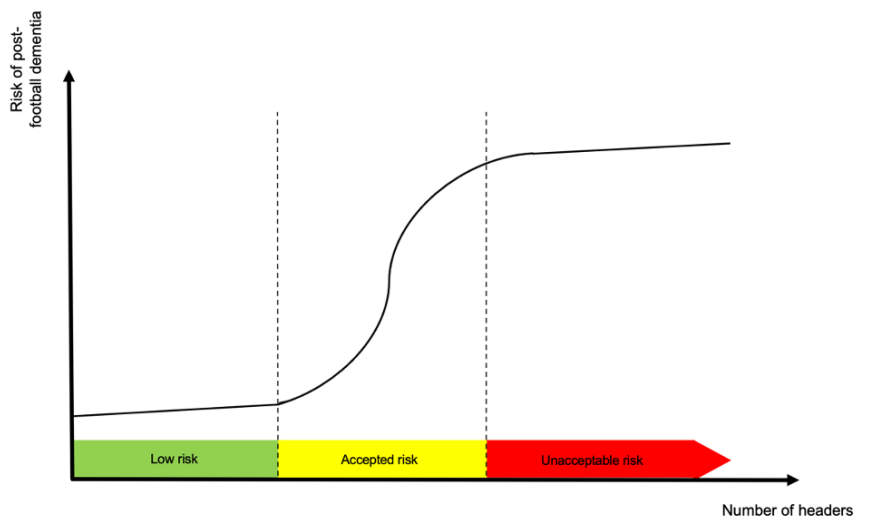

Figure 1 Fictive dose-response relationship between the number of heading (eg, per season) and the risk of dementia among professional footballers. this to be evidence-based, then sufficient evidence would be needed on the causal and dose-response relationship between heading and the risk of dementia among professional footballers for decision-makers to define exposure thresholds below which the risk of postfootball dementia is low or accepted. At present time, we do not have this evidence.

\section{Evidence-based or not?}

The current call to reduce heading in professional football to prevent dementia among both male and female professional footballers is not evidence-based. Empirical knowledge needs to be gathered in large cohort studies among male and female professional footballers, with an accurate assessment of heading exposure (ie, observed and not self-reported) and a thorough control in the extent to which other dementia risk factors are controlled. Once the causal and dose-response relationship established and once exposure thresholds for low or accepted risk of postfootball dementia defined, an important question will be who remains responsible and thus accountable for the respect of safe headers exposure thresholds?

Twitter Vincent Gouttebarge @VGouttebarge

Contributors VG conceptualised and wrote the manuscript.

Funding The author has not declared a specific grant for this research from any funding agency in the public, commercial or not-for-profit sectors.

Competing interests None declared.

Patient consent for publication Not required.

Provenance and peer review Not commissioned; externally peer reviewed.

Open access This is an open access article distributed in accordance with the Creative Commons Attribution Non Commercial (CC BY-NC 4.0) license, which permits others to distribute, remix, adapt, build upon this work non-commercially, and license their derivative works on different terms, provided the original work is properly cited, appropriate credit is given, any changes made indicated, and the use is non-commercial. See: http://creativecommons.org/licenses/by-nc/4.0/.

\section{ORCID iD}

Vincent Gouttebarge http://orcid.org/0000-0002-0126-4177

\section{REFERENCES}

1 Livingston G, Huntley J, Sommerlad A, et al. Dementia prevention, intervention, and care: 2020 report of the Lancet Commission. Lancet 2020;396:413-46.

2 Mackay DF, Russell ER, Stewart K, et al. Neurodegenerative disease mortality among former professional soccer players. N Engl J Med 2019;381:1801-8.

3 Tierney GJ, Higgins B. The incidence and mechanism of heading in European professional football players over three seasons. Scand $J$ Med Sci Sports 2020.

4 Sandmo SB, Gooijers J, Seer C, et al. Evaluating the validity of selfreport as a method for quantifying heading exposure in male youth soccer. Res Sports Med 2020:1-13.

5 Lehman EJ, Hein MJ, Baron SL, et al. Neurodegenerative causes of death among retired National football League players. Neurology 2012;79:1970-4.

6 Bouter LM, Zielhuis GA, Zeegers MPA. Textbook of epidemiology. Houten: Bohn Stafleu van Loghum, 2018.

7 Pandey A, Salahuddin U, Garg S, et al. Continuous dose-response association between sedentary time and risk for cardiovascular disease: a meta-analysis. JAMA Cardiol 2016;1:575-83.

8 Bull FC, Al-Ansari SS, Biddle S, et al. World Health organization 2020 guidelines on physical activity and sedentary behaviour. $\mathrm{Br} J$ Sports Med 2020;54:1451-62. 